\title{
OUTCOME OF VALVE REPAIR AND THE COX MAZE PROCEDURE FOR MITRAL REGURGITATION AND ASSOCIATED ATRIAL FIBRILLATION
}

Nobuhiro Handa, MDa

Hartzell V. Schaff, MD

James J. Morris, MD

Betty J. Anderson, RN ${ }^{\mathrm{a}}$

Stephen L. Kopecky, MD ${ }^{\mathrm{b}}$

Maurice Enriquez-Sarano, MD $^{\mathrm{b}}$
Objective: The objective was to determine whether the Cox maze procedure provides adjunctive benefit in patients with atrial fibrillation undergoing mitral valve repair. Methods: We compared the outcome of 39 patients who had the Cox maze procedure plus mitral valve repair between January 1993 and December 1996 (maze group) with that of 58 patients with preoperative atrial fibrillation who had mitral valve repair during the same interval by the same surgeons (control group). Patients in the 2 cohorts were similar for age, gender, preoperative New York Heart Association class III or IV, and duration of preoperative atrial fibrillation. The control group had a higher incidence of previous heart surgery and coronary artery disease. Results: No operative deaths occurred, and 1 patient in each group required pacemaker implantation after the operation. Duration of cardiopulmonary bypass (122 $\pm 40 \mathrm{~min}$ utes vs $58 \pm 27$ minutes, $P<.0001)$ and hospitalization $(12.6 \pm 6.4$ vs 9.3 \pm 3.4 days, $P<.0025$ ) were prolonged in patients having the Cox maze procedure. Overall, 2-year survival was similar $(92 \% \pm 5 \%$ for maze patients and $96 \% \pm 3 \%$ for controls). Freedom from atrial fibrillation in the maze group was $74 \% \pm 8 \% 2$ years after the operation compared with $27 \% \pm 7 \%$ for the control group $(P<.0001)$. Freedom from stroke or anticoagulant-associated bleeding in the maze group was $100 \% 2$ years after the operation compared with $90 \% \pm 8 \%$ in the control group $(P=.04)$. At most recent follow-up, $82 \%$ of maze patients were in normal sinus rhythm (53\% in control group). Conclusion: The addition of the Cox maze procedure to mitral valve repair is safe and effective for selected patients, and elimination of atrial fibrillation decreased late complications. (J Thorac Cardiovasc Surg 1999;118:628-35)
A pproximately $30 \%$ to $40 \%$ of patients who undergo mitral valve repair have chronic atrial fibrillation before the operation, ${ }^{1-4}$ and the majority remain in atrial fibrillation after the operation. One study reported that mitral valve repair more than 3 months after the onset of atrial fibrillation failed to restore normal atrial contraction..$^{5}$

From the Divisions of Thoracic and Cardiovascular Surgery a and Cardiovascular Diseases and Internal Medicine, ${ }^{\mathrm{b}}$ Mayo Clinic and Mayo Foundation, Rochester, Minn.

Read at the Seventieth Scientific Sessions of the American Heart Association, Orlando, Fla, November 9-12, 1997.

Received for publication Jan 4, 1999; revisions requested March 4, 1999; revisions received June 18, 1999; accepted for publication June 29, 1999.

Address for reprints: Hartzell V. Schaff, MD, Mayo Clinic, 200 First Street SW, Rochester, MN 55905.

Copyright (C) 1999 by Mosby, Inc.

$0022-5223 / 99 \$ 8.00+0 \quad \mathbf{1 2 / 1 / 1 0 1 2 0 1}$
In patients with severe mitral valve regurgitation and atrial fibrillation, the Cox maze procedure ${ }^{6-10}$ has not been used routinely by most surgeons because of the generally low risk of postoperative thromboembolism and because of the potential of this additional procedure to increase the mortality of valve repair. Although several authors have reported that atrial fibrillation was successfully ablated with the Cox maze procedure in patients undergoing mitral valve procedures, ${ }^{7-10}$ no data demonstrate a long-term benefit of reduced late morbidity and mortality associated with the elimination of atrial fibrillation. We have used the Cox maze procedure in conjunction with valve repair in patients with severe mitral regurgitation and atrial fibrillation, anticipating a low risk of thromboemboli when sinus rhythm is maintained and the long-term benefit of avoiding anticoagulation with warfarin. The purpose of this study was to assess the early- and intermediate-term results of this combined procedure. 
Table I. Comparison of preoperative clinical characteristics of control and maze groups

\begin{tabular}{|c|c|c|c|}
\hline Variable & $\begin{array}{l}\text { Control group } \\
\quad(n=58)\end{array}$ & $\begin{array}{l}\text { Maze group } \\
\quad(n=39)\end{array}$ & $\mathrm{P}$ value \\
\hline Male sex, No. (\%) & $39(67)$ & $23(59)$ & .41 \\
\hline Age, mean \pm SD $(y)$ & $69 \pm 19$ & $65 \pm 13$ & .13 \\
\hline $\begin{array}{l}\text { NYHA class III or IV, } \\
\text { No. }(\%)\end{array}$ & $51(88)$ & $30(77)$ & .15 \\
\hline $\begin{array}{l}\text { History of rheumatic fever, } \\
\text { No. }(\%)\end{array}$ & $4(7)$ & $6(15)$ & 19 \\
\hline History of stroke, No. (\%) & $4(7)$ & $4(10)$ & .71 \\
\hline $\begin{array}{l}\text { Previous heart surgery, } \\
\text { No. }(\%)\end{array}$ & $8(14)$ & $0(0)$ & .02 \\
\hline Coronary artery disease (\%) & $26(45)$ & $8(21)$ & .01 \\
\hline $\begin{array}{l}\text { History of previous MI, } \\
\text { No. }(\%)\end{array}$ & $5(9)$ & $3(8)$ & 1.00 \\
\hline $\begin{array}{l}\text { History of cardioversion, } \\
\text { No. }(\%)\end{array}$ & $6(10)$ & $4(10)$ & 1.00 \\
\hline Chronic AF, No. (\%) & $36(62)$ & $31(79)$ & .07 \\
\hline $\begin{array}{l}\text { Duration of chronic } \mathrm{AF},{ }^{*} \\
\text { mean } \pm \mathrm{SD}(\mathrm{mo})\end{array}$ & $28 \pm 53$ & $45 \pm 63$ & .03 \\
\hline $\begin{array}{l}\text { Duration of chronic AF, } \\
\text { mean } \pm \mathrm{SD}(\mathrm{mo})\end{array}$ & $42 \pm 62$ & $58 \pm 66$ & .25 \\
\hline
\end{tabular}

$A F$, Atrial fibrillation; $M I$, myocardial infarction; $N Y H A$, New York Heart Association; $S D$, standard deviation.

*Paroxysmal AF is considered as 0 months of chronic AF.

\section{Patients and methods}

Between January 1993 and December 1996, 97 consecutive patients with a history of atrial fibrillation underwent mitral valve repair for mitral regurgitation on 2 hospital services; all patients had chronic atrial fibrillation or multiple episodes of paroxysmal atrial fibrillation before the operation. Of the 97 patients, 39 had mitral valve repair with the Cox maze procedure and formed the maze group, and the other 58 had valve repair alone and formed the control group.

For this study, we retrospectively reviewed and collected data from operative notes, anesthesia records, clinical case histories, and laboratory investigations, including electrocardiograms, echocardiograms, and cardiac catheterization reports. Follow-up data were collected from Mayo Clinic records of outpatient visits and correspondence with patients and referring physicians. A total of 204 clinical, hemodynamic, electrocardiographic, and echocardiographic variables were entered into a computerized database and analyzed. Follow-up data more than 6 months after the operations were available for all patients.

Patients. Demographic data and pertinent cardiac information are given in Table I. Groups were similar in age, gender distribution, and New York Heart Association (NYHA) functional class. Similar proportions of patients in each group had previous myocardial infarction, stroke, rheumatic fever, or cardioversion. The decision to add the Cox maze procedure was made by the surgeon; these patients represent the first group to have combined procedures at our clinic. Eight patients in the control group had previous heart surgery, but
Table II. Comparison of causes of mitral regurgitation in the control and maze groups

\begin{tabular}{|c|c|c|c|c|c|c|}
\hline \multirow[b]{3}{*}{ Cause } & \multicolumn{3}{|c|}{$\begin{array}{l}\text { Control group } \\
\quad(n=58)\end{array}$} & \multicolumn{3}{|c|}{$\begin{array}{l}\text { Maze group } \\
\quad(n=39)\end{array}$} \\
\hline & & & $95 \%$ & & & $95 \%$ \\
\hline & No. & $\%$ & $C I$ & No. & $\%$ & $C I$ \\
\hline Ruptured chordae & 31 & 53 & $0-67$ & 10 & 26 & $13-42$ \\
\hline $\begin{array}{l}\text { Prolapse (elongated } \\
\text { chordae) }\end{array}$ & 11 & 19 & $10-31$ & 10 & 26 & $13-42$ \\
\hline Ischemic & 5 & 9 & $3-19$ & 5 & 13 & $4-27$ \\
\hline Rheumatic & 4 & 7 & $2-17$ & 4 & 10 & $3-24$ \\
\hline Endocarditis & 4 & 7 & $2-17$ & 4 & 10 & $3-24$ \\
\hline Other & 3 & 5 & $1-14$ & 6 & 15 & $6-31$ \\
\hline
\end{tabular}

no patient in the maze group had previous heart surgery $(P=$ $.02)$. Also, associated coronary artery disease was more frequent in the control group than in the maze group $(P=.01)$.

With respect to preoperative heart rhythm, $80 \%$ of patients in the maze group were in chronic atrial fibrillation, compared with $62 \%$ in the control group. The Cox maze procedure was applied to the patients who had multiple episodes of paroxysmal atrial fibrillation necessitating long-term anticoagulation before the operation. Three patients in the control group had a permanent pacemaker inserted at different times before mitral valve repair. The duration of preoperative chronic atrial fibrillation was significantly longer in patients in the maze group than in the control group ( $45 \pm 63$ months vs $28 \pm 53$ months, $P=.03$ ).

Surgical procedure. Methods of mitral valve repair varied according to the pathologic findings; an annuloplasty ring was used in almost all patients. The maze III procedure described by Cox and associates ${ }^{11,12}$ was used.

Statistical methods. Comparisons of the characteristics between the 2 patient groups were carried out with $\chi^{2}$ tests or Fisher's exact tests for nominal variables, with 2 -sample $t$ tests or Wilcoxon rank sum tests for continuous variables, and with Wilcoxon rank sum tests for ordinal variables. Survival and survivorship free of atrial fibrillation, bleeding, and stroke were estimated by means of the Kaplan-Meier method. Survivorship curves were compared with the logrank test. The relationships of continuous variables to survivorship and the multivariate relationship of multiple risk factors to survival were evaluated with the Cox proportional hazards model.

\section{Results}

Pathophysiology of mitral regurgitation and operative findings. The causes of mitral regurgitation are summarized in Table II. The most common cause was mitral valve prolapse with either ruptured chordae or elongated chordae. More than 50\% of patients in both groups had posterior leaflet repair with either plication 


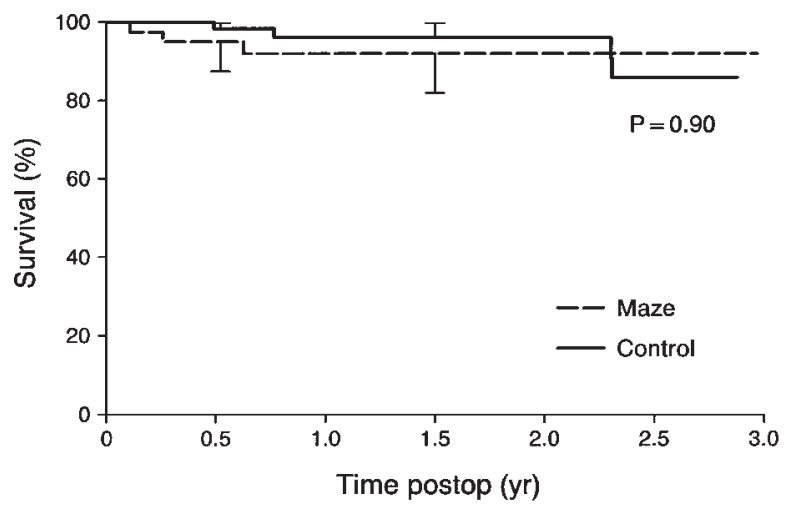

Fig 1. Actuarial survival analyses. postop, Postoperatively. Free of event: death $P=.90$.

\begin{tabular}{lclc} 
& \multicolumn{1}{c}{ Maze group } & & Control group \\
\cline { 2 - 2 } & Survival (No. at risk) & & Survival (No. at risk) \\
\hline One year & $91.8 \% \pm 4.6 \%(26)$ & & $96.0 \% \pm 2.8 \%(36)$ \\
Two years & $91.8 \% \pm 4.6 \%(15)$ & & $96.0 \% \pm 2.8 \%(22)$ \\
Three years & $91.8 \% \pm 4.6 \%(3)$ & & $85.9 \% \pm 7.2 \%(11)$ \\
\hline
\end{tabular}

or partial resection and suture repair. Anterior leaflet repairs were undertaken in approximately $25 \%$ to $30 \%$ of patients, and posterior ring annuloplasty was used in almost all patients (95\% in the control group and $97 \%$ in the maze group).

Aortic crossclamp time and cardiopulmonary bypass time were significantly longer in the maze group than in the control group (aortic crossclamp time, $36 \pm 14$ minutes vs $69 \pm 18$ minutes [P <.0001]; cardiopulmonary bypass time, $58 \pm 27$ minutes vs $122 \pm 40$ minutes [P <.0001]). Seventy-one percent of patients in the control group were maintained on normothermic cardiopulmonary bypass, compared with only $40 \%$ of patients in the maze group $(P<.0001)$.

Associated procedures included coronary artery bypass grafting $(n=28)$, repair of atrial septal defects or patent foramen ovale $(n=14)$, tricuspid valve repair $(\mathrm{n}=6)$, pericardiectomy $(\mathrm{n}=1)$, and aortic valve replacement with tissue valve $(\mathrm{n}=1)$. There was no difference between the 2 groups in terms of incidence of associated procedures except that concomitant coronary artery bypass grafting was performed in 7 patients in the maze group (18\%) and 21 patients in the control group (36\%) $(P=.05)$.

Postoperative morbidity and mortality. No in-hospital deaths occurred in either group. Hospital stay in the maze group was prolonged compared with that in the control group $(12.6 \pm 6.4$ days vs $9.3 \pm 3.4$ days, $P$ $=.003)$. Postoperative complications included bleeding $(\mathrm{n}=5)$, respiratory failure (intubation $>72$ hours $)(\mathrm{n}=$

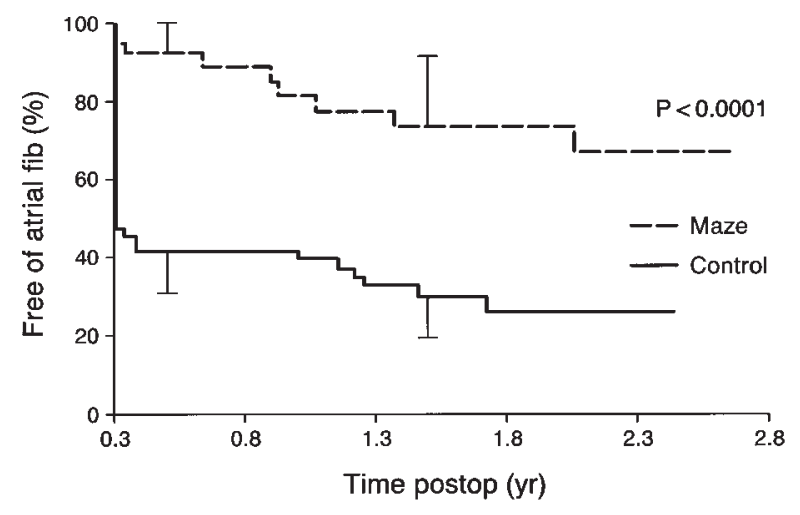

Fig 2. Survival analyses of freedom from recurrent atrial fibrillation starting at 3 months after operation. fib, Fibrillation; postop, postoperatively. Free of event: atrial fibrillation $P<.001$.

\begin{tabular}{|c|c|c|}
\hline & Maze group & Control group \\
\hline & Survival (No. at risk) & Survival (No. at risk) \\
\hline Three months & $94.7 \% \pm 3.6 \%$ & $46.6 \% \pm 6.5 \%(27)$ \\
\hline One year & $81.5 \% \pm 6.9 \%(21)$ & $41.2 \% \pm 6.5 \%$ \\
\hline Two years & $73.5 \% \pm 8.2 \%(12)$ & $26.3 \% \pm 6.5 \%$ \\
\hline
\end{tabular}

2), intra-aortic balloon pump insertion $(n=2)$, pneumonitis $(n=2)$, pneumothorax $(n=1)$, and gastrointestinal bleeding $(n=1)$. One patient in each group required postoperative pacemaker implantation for junctional bradycardia. There was no difference between the 2 groups in the incidence of complications.

Survival and late events. All patients were observed for a minimum of 6 months after the operation. Overall 2-year survival was similar for the 2 groups (maze group, $92 \% \pm 5 \%$; control group, $96 \% \pm 3 \%$; Fig 1). There were 7 late deaths. In the maze group, 1 patient died of congestive heart failure, 1 had ventricular tachycardia, and another died of an unknown cause. In the control group, 4 late deaths were due to pulmonary embolism, intracerebral hemorrhage, cerebral infarction, and myocardial infarction. Three patients ( 1 in the control group, 2 in the maze group) required reoperation for recurrent mitral valve regurgitation ( 2 patients) or hemolysis.

Because early postoperative atrial fibrillation may be caused by mechanisms other than chronic atrial fibrillation, we chose to analyze occurrence of the arrhythmia after the first 3 postoperative months. As seen in Fig 2, freedom from atrial fibrillation in patients in the maze group was $74 \% \pm 8 \% 2$ years after operation, compared with $27 \% \pm 7 \%$ for patients in the control group $(P<.0001)$.

There were other significant differences in late events 


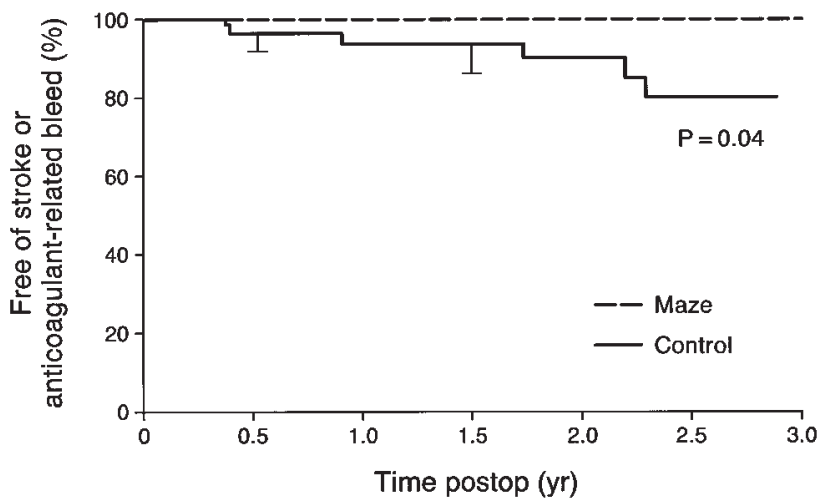

Fig 3. Survival analyses of freedom from combined stroke and anticoagulant-related bleeding. postop, Postoperatively. Free of event: stroke or anticoagulant-related bleeding $P=.04$.

\begin{tabular}{|c|c|c|}
\hline & Maze group & Control group \\
\hline & Survival (No. at risk) & Survival (No. at risk) \\
\hline One year & $100.0 \% \pm 0.0 \%$ & $94.0 \% \pm 3.4 \%$ \\
\hline Two years & $100.0 \% \pm 0.0 \%$ & $90.1 \% \pm 5.0 \%(21)$ \\
\hline
\end{tabular}

Table III. Comparison of heart rhythm in the control and maze groups

\begin{tabular}{|c|c|c|c|c|c|c|c|c|}
\hline \multirow[b]{3}{*}{ Rhythm } & \multicolumn{4}{|c|}{ Dismissal } & \multicolumn{4}{|c|}{ Most recent } \\
\hline & \multicolumn{2}{|c|}{$\begin{array}{l}\text { Control group } \\
\quad(n=58)\end{array}$} & \multicolumn{2}{|c|}{$\begin{array}{l}\text { Maze group } \\
(n=39)\end{array}$} & \multicolumn{2}{|c|}{$\begin{array}{c}\text { Control group } \\
(n=58)\end{array}$} & \multicolumn{2}{|c|}{$\begin{array}{l}\text { Maze group } \\
\quad(n=39)\end{array}$} \\
\hline & No. & $\%$ & No. & $\%$ & No. & $\%$ & No. & $\%$ \\
\hline Normal sinus & 25 & 43 & 28 & 72 & 31 & 53 & $32^{*}$ & 82 \\
\hline Atrial flutter & 3 & 5 & 0 & 0 & 1 & 2 & 2 & 5 \\
\hline Atrial fibrillation & 24 & 41 & 2 & 5 & 21 & 36 & 4 & 10 \\
\hline Junctional & 1 & 2 & 9 & 23 & 0 & 0 & 1 & 3 \\
\hline $\begin{array}{l}\text { Pacemaker rhythm with } \\
\text { underlying atrial fibrillation }\end{array}$ & 5 & 9 & 0 & 0 & 5 & 9 & 0 & 0 \\
\hline
\end{tabular}

Proportion of atrial fibrillation at dismissal is significantly different between control group and maze group $(P<.001)$.

"Includes 1 patient with ectopic atrial rhythm.

between the 2 groups. Late complications of bleeding and stroke were fewer in the maze group. In the maze group, no patient had a stroke, and 1 patient who did not receive anticoagulation treatment with warfarin had a hemorrhagic complication. In contrast, in the control group, 4 patients had strokes and 4 had bleeding (1 event not associated with warfarin).

Freedom from stroke and bleeding at 2 years was $95 \%$ $\pm 5 \%$ in the maze group and $86 \% \pm 6 \%$ in the control group $(P=.08)$. If we consider only bleeding associated with warfarin treatment, freedom from combined stroke and bleeding at 2 years was $100 \%$ in the maze group and $90 \% \pm 8 \%$ in the control group ( $P=.04$; Fig 3$)$.

Electrocardiogram. At the time of hospital dismissal, 95\% of patients in the maze group were free of atrial fibrillation, compared with $50 \%$ of those in the control group (Table III). At dismissal, 10 patients had junctional rhythm, 9 of them in the maze group. Of these 9 patients, 4 later converted to normal sinus rhythm, 2 to atrial fibrillation, and 2 to atrial flutter; the 1 other patient had pacemaker placement during hospitalization and was still in junctional rhythm at follow-up.

With the most recent electrocardiogram, $82 \%$ of patients in the maze group were in normal sinus rhythm, compared with $53 \%$ in the control group. Of note, $77 \%$ of patients with preoperative chronic atrial fibrillation converted to normal sinus rhythm after the Cox maze procedure, compared with only $31 \%$ of those in the control group.

The relationship between return of sinus rhythm and duration of preoperative atrial fibrillation is shown in Table IV. Only $18.5 \%$ of patients in the control group 
Table IV. Comparison of restoration of normal sinus rhythm in the control and maze groups

\begin{tabular}{|c|c|c|c|c|c|c|}
\hline \multirow[b]{2}{*}{$\begin{array}{l}\text { Duration of } \\
\text { preoperative AF }\end{array}$} & \multicolumn{3}{|c|}{ Control group $(n=58)$} & \multicolumn{3}{|c|}{ Maze group $(n=39)$} \\
\hline & $\begin{array}{c}\text { No. of } \\
\text { patients }\end{array}$ & $\begin{array}{l}\text { No. in } \\
\text { NSR }\end{array}$ & $\%$ & $\begin{array}{c}\text { No. of } \\
\text { patients }\end{array}$ & $\begin{array}{l}\text { No. in } \\
\text { NSR }\end{array}$ & $\%$ \\
\hline Paroxysmal AF & 22 & 20 & 91 & 8 & 8 & 100 \\
\hline \multicolumn{7}{|l|}{ Chronic AF } \\
\hline$\leq 3 \mathrm{mo}$ & 7 & 4 & 57 & 4 & 3 & 75 \\
\hline 4-12 mo & 7 & 1 & 14 & 5 & 4 & 80 \\
\hline $12 \mathrm{mo}$ & 20 & 4 & 20 & 20 & 15 & 75 \\
\hline Unknown & 2 & 2 & 100 & 2 & 2 & 100 \\
\hline
\end{tabular}

$A F$, Atrial fibrillation; $N S R$, normal sinus rhythm.

Table V. Results of univariable analysis of risk factors for recurrence of atrial fibrillation

\begin{tabular}{lccc}
\hline Variable & P value & Hazard ratio & $95 \%$ CI \\
\hline No Cox maze procedure & $<.00001$ & 4.27 & $2.07,8.85$ \\
$\begin{array}{l}\text { Preoperative left atrial } \\
\quad \text { dimension }\end{array}$ & .01 & 1.05 & $1.01,1.10$ \\
$\quad$ & & 2.01 & $1.03,4.03$ \\
Chronic atrial fibrillation & .05 & 1.71 & $0.96,3.03$ \\
$\begin{array}{l}\text { MR on most recent } \\
\quad \text { echocardiogram }\end{array}$ & .054 & & \\
$\quad$ Gender & .32 & 1.37 & $0.75,2.48$ \\
$\quad \begin{array}{l}\text { Preoperative ejection } \\
\text { fraction }\end{array}$ & .40 & 0.99 & $0.96,1.02$ \\
$\quad \begin{array}{l}\text { TR on most recent } \\
\text { echocardiogram }\end{array}$ & .41 & 1.28 & $0.72,2.29$ \\
$\quad$ Duration of chronic & .65 & 1.00 & $1.00,1.01$ \\
atrial fibrillation & & & \\
\hline
\end{tabular}

$C I$, Confidence interval; $M R$, mitral regurgitation; $T R$, tricuspid regurgitation.

who had chronic atrial fibrillation more than 3 months regained normal sinus rhythm. In the maze group, $76 \%$ of patients who had chronic atrial fibrillation longer than 3 months regained normal sinus rhythm (Table IV).

Risk factors for recurrence of atrial fibrillation. Risk factors for recurrence of atrial fibrillation were assessed by univariable analysis (Table V). Omission of a Cox maze procedure, larger preoperative left atrial dimension, and chronic atrial fibrillation were significant risk factors for recurrence of atrial fibrillation. Multivariable analysis, however, demonstrated that only omission of the Cox maze procedure $(P=.0007)$ and chronic atrial fibrillation $(P=.03)$ were independent risk factors for recurrence of atrial fibrillation (Table VI). Preoperative left atrial dimension was not associated with recurrence of atrial fibrillation $(P=$ .14). On the basis of these results, we constructed survival curves of freedom from recurrent atrial fibrillation stratified by type of atrial fibrillation (paroxysmal versus chronic) and maze versus control (Fig 4). Patients with preoperative paroxysmal atrial fibrillation
Table VI. Results of multivariable analysis of risk factors for recurrence of atrial fibrillation

\begin{tabular}{llcl}
\hline Variable & P value & Hazard ratio & $95 \%$ CI \\
\hline No Cox maze procedure & .0007 & 4.4 & $1.9,10.5$ \\
Chronic atrial fibrillation & .03 & 3.3 & $1.1,9.8$ \\
Preoperative left atrial & .14 & 1.0 & $1.0,1.1$ \\
dimension & & & \\
CI, Confidence interval. & & &
\end{tabular}

who had the Cox maze procedure were completely free of recurrent atrial fibrillation.

Antiarrhythmic drugs and warfarin. We routinely resumed treatment with most antiarrhythmic agents prescribed before the operation for a period of 6 to 8 weeks after the operation, and warfarin also was prescribed routinely for 3 to 6 months after mitral valve repair. Decisions about use of medications were supervised by the local attending cardiologist or general physician.

The spectrum and intensity of preoperative antiarrhythmic therapy were comparable for the 2 groups, but after operation, the number of antiarrhythmic drugs decreased over time in the maze group from $1.31 \pm$ 0.69 to $0.71 \pm 0.76$ at follow-up, compared with $1.26 \pm$ 0.78 to $1.16 \pm 0.79$ for the control group $(P=.01)$. In the maze group, $45 \%$ of patients were free of all antiarrhythmic agents at most recent follow-up, compared with $22 \%$ in the control group $(P=.02)$.

With respect to warfarin, $63 \%$ of patients in the maze group were not taking warfarin compared with $50 \%$ in the control group, but this difference did not reach statistical significance. However, 9 patients $(23 \%)$ who had no episodes of atrial fibrillation after surgery are still taking warfarin, and the drug presumably may be safely discontinued. In addition, 5 patients in the control group who had a permanent pacemaker for profound bradycardia with underlying atrial fibrillation stopped taking warfarin. 


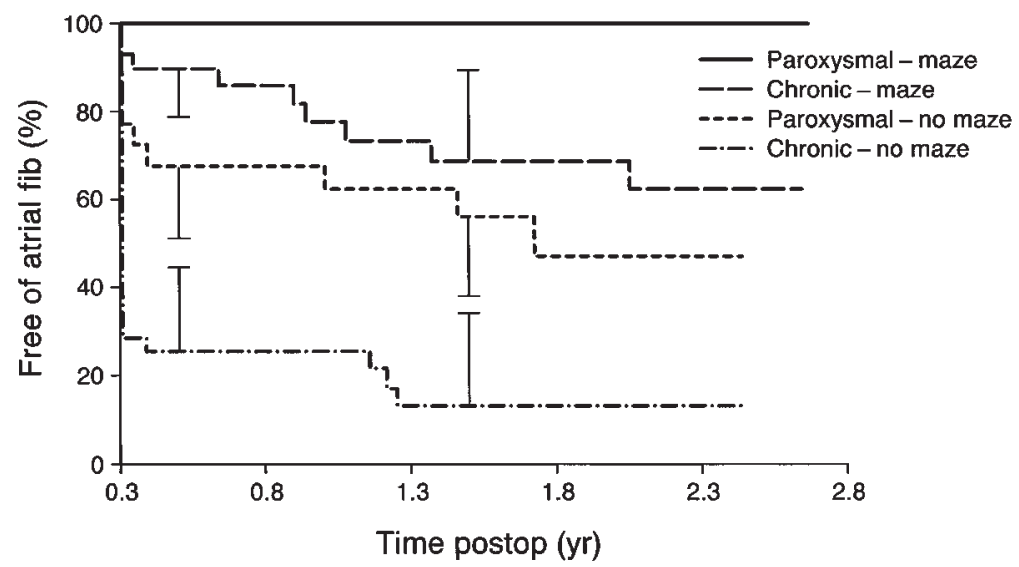

Fig 4. Survival analyses of freedom from recurrent atrial fibrillation starting 3 months after operation stratified by type of atrial fibrillation (chronic vs paroxysmal) and Cox maze procedure (maze vs control). fib, Fibrillation. Free of event: atrial fibrillation.

\begin{tabular}{|c|c|c|}
\hline & Paroxysmal-maze group & Paroxysmal_control group \\
\hline & Survival (No. at risk) & Survival (No. at risk) \\
\hline Three months & $100.0 \% \pm 0.0 \%$ & $77.3 \% \pm 8.9 \%(17)$ \\
\hline One year & $100.0 \% \pm 0.0 \%(21)$ & $68.2 \% \pm 9.9 \%(12)$ \\
\hline \multirow[t]{3}{*}{ Two years } & $100.0 \% \pm 0.0 \%(12)$ & $46.9 \% \pm 1.3 \%(5)$ \\
\hline & Chronic-maze group & Chronic_control group \\
\hline & Survival (No. at risk) & Survival (No. at risk) \\
\hline Three months & $93.3 \% \pm 4.6 \%(27)$ & $27.8 \% \pm 7.5 \%(26)$ \\
\hline One year & $78.1 \% \pm 8.0 \%(18)$ & $24.7 \% \pm 7.2 \%(6)$ \\
\hline Two years & $73.5 \% \pm 8.2 \%(12)$ & $12.3 \% \pm 6.2 \%(3)$ \\
\hline
\end{tabular}

\section{Discussion}

The Cox maze procedure was designed to prevent reentrant atrial fibrillation, ${ }^{13}$ and several series have confirmed the success of the operation. ${ }^{6,14}$ As a result, indications have been extended from lone atrial fibrillation to treatment of atrial fibrillation in patients having cardiac surgery for associated mitral valve disease, atrial septal defect, or other organic cardiac disease. ${ }^{8-11}$ The restoration of normal sinus rhythm brings symptomatic relief of palpitation and better atrial transport function. ${ }^{4}$ However, the most important potential benefit of the Cox maze procedure is reduction in risks of thromboembolism and anticoagulant-associated bleeding.

Atrial fibrillation is prevalent among patients referred for operations on the mitral valve; previous studies have shown that approximately $30 \%$ to $40 \%$ of patients were in chronic atrial fibrillation when mitral valve repair was scheduled. ${ }^{1-5}$ In our experience, approximately $80 \%$ of the patients who had preoperative chronic atrial fibrillation more than 3 months before the operation remained in atrial fibrillation after successful mitral valve repair. ${ }^{5}$ In the present investigation, the adjunctive Cox maze procedure increased the restoration of normal sinus rhythm to $82 \%$ of patients, a finding similar to that of other studies ${ }^{8-10}$ Furthermore, our data suggest that concomitant Cox maze procedure reduced the combined risks of stroke and anticoagulant-related bleeding, as well as decreased the need for antiarrhythmic drugs.

Risks of stroke in nonrheumatic atrial fibrillation have been studied extensively in regard to primary prevention ${ }^{15-18}$ and secondary prevention. ${ }^{19,20}$ Recent prospective studies have shown that the risk of stroke in placebo-treated patients with atrial fibrillation is $5 \%$ to $8 \%$ per year. ${ }^{15,16,18}$ The reduction in risk of stroke by anticoagulation with warfarin ranges from $37 \%$ to $86 \%$, but chronic anticoagulation with warfarin carries a risk of bleeding from $0.5 \%$ to $2.8 \%$ per year. ${ }^{21,22}$ Furthermore, anticoagulation with warfarin requires careful follow-up and adjustment of dosage; use of a low dose of warfarin and aspirin without monitoring 
the international normalized ratio is not as effective as conventional anticoagulation with warfarin. ${ }^{23}$

Maintenance of sinus rhythm and avoidance of anticoagulation with warfarin may reduce medical expenses; long-term anticoagulation with warfarin is estimated to cost about $\$ 800$ per person annually in the United States. ${ }^{24}$ Medical expenditures for care of patients with stroke or bleeding also are substantial. ${ }^{24}$ In the early results of the present study with 21 months of mean follow-up, about $36 \%$ of patients in the maze group (50\% in the control group) were still taking warfarin. We expect that the majority of patients in the maze group who are in sinus rhythm eventually will discontinue taking warfarin.

An additional benefit of concomitant Cox maze procedure for restoration of sinus rhythm is reduced need for antiarrhythmic agents. The results of the Cardiac Arrhythmia Suppression Test (CAST) study and other clinical trials suggested that antiarrhythmic agents commonly used for atrial fibrillation, such as quinidine and amiodarone, have proarrhythmic effects. ${ }^{25-27}$ After the Cox maze procedure, the number of antiarrhythmic drugs was decreased, and $44 \%$ of patients were free of antiarrhythmic therapy.

The major limitation of our study is that it was not randomized, and there were some differences in the baseline characteristics of patients in the 2 groups. The decision for or against an adjunctive Cox maze procedure reflected the surgeon's experience with the procedure, as well as the anticipated difficulty with mitral valve repair. With experience, however, we rarely decided against a concomitant Cox maze procedure on the basis of the planned operation; more often, local factors such as extreme fragility of tissue, unusual bleeding, or poor exposure militated against a concomitant maze procedure. Selection bias is reflected by the absence of patients with previous cardiac operations and coronary artery disease in the maze group. However, we do not consider previous heart surgery alone to be a contraindication to the procedure and have successfully performed the Cox maze procedure in several patients having second or third procedures.

Of interest, the duration of preoperative atrial fibrillation was longer in the maze group than in the control group, and the proportion of patients in chronic atrial fibrillation was also greater; these factors would be expected to increase the risk of late atrial fibrillation. Among patients in the control group who had chronic atrial fibrillation more than 3 months, only $18.5 \%$ had a return of sinus rhythm (Table IV). In the maze group, $76 \%$ of patients who had chronic atrial fibrillation longer than 3 months regained normal sinus rhythm.
Thus the addition of the Cox maze procedure appears to be particularly useful in patients with chronic atrial fibrillation of more than 3 months' duration. Of note, survival free of recurrent atrial fibrillation in a control group with paroxysmal atrial fibrillation was only $49 \%$ $\pm 1 \%$ at 2 years (Fig 4). The complete suppression of paroxysmal atrial fibrillation with the Cox maze procedure in this study suggests that the combined operation may be of benefit for patients who have multiple episodes of paroxysmal atrial fibrillation necessitating long-term anticoagulation before mitral valve repair.

Some groups have advocated only the left-sided incisions to ablate atrial fibrillation in patients having mitral valve repair or replacement to reduce morbidity and mortality. ${ }^{28}$ In our series, there was little difference in either survival or perioperative morbidity between patients having valve repair with and those having valve repair without concomitant maze procedure, and it is unlikely that limiting the incisions to the left atrium would have influenced the clinical results.

Reduction of left atrial size by resection of atrial muscle at the time of the Cox maze procedure has been described. ${ }^{7}$ However, multivariable analysis of our data did not confirm that preoperative left atrial size was predictive of recurrence of atrial fibrillation. Therefore the role of additional resection to reduce atrial size during the Cox maze procedure is questionable.

Although 9 patients who had the Cox maze procedure were in junctional rhythm at the time of hospital dismissal, only 1 required a permanent pacemaker and 4 of the 9 had return of sinus rhythm. In the experience at Barnes Hospital, 25\% of patients who had the Cox maze procedure required permanent pacemaker placement. ${ }^{29}$ Persistent junctional rhythm may indicate longstanding sinus node dysfunction and, certainly, this predisposes patients to reentrant atrial arrhythmias and stroke. ${ }^{30}$ Among the other 4 patients with junctional rhythm at dismissal, recurrent atrial fibrillation developed in 2 and atrial flutter in 2. It has been reported that up to 50 weeks are required until normal sinus rhythm is restored. ${ }^{7}$ Theophylline therapy was proposed for early sinus node dysfunction with slow junctional rhythm after the Cox maze procedure, ${ }^{7}$ but we have not used this.

Our experience suggests that the Cox maze operation is a safe and reliable adjunctive procedure for selected patients with atrial fibrillation undergoing mitral valve repair. It seems particularly useful for patients with chronic atrial fibrillation of more than 3 months' duration before the operation. Perioperative morbidity and mortality are very low. Early follow-up documents restoration of sinus rhythm in more than $75 \%$ of 
patients and reduced risks of thromboembolism and bleeding due to warfarin. Although the addition of the Cox maze procedure lengthens hospital stay in patients having mitral valve repair, overall medical costs may be decreased by reducing the need for long-term anticoagulation, as well as costs associated with stroke and bleeding complications.

\section{REFERENCES}

1. Cohn LH, Couper GS, Aranki SF, Rizzo RJ, Kinchla NM, Collins JJ Jr. Long-term results of mitral valve reconstruction for regurgitation of the myxomatous mitral valve. J Thorac Cardiovasc Surg 1994;107:143-50.

2. David TE, Armstrong S, Sun Z, Daniel L. Late results of mitral valve repair for mitral regurgitation due to degenerative disease. Ann Thorac Surg 1993;56:7-12.

3. Alvarez JM, Deal CW, Loveridge K, et al. Repairing the degenerative mitral valve: ten- to fifteen-year follow-up. J Thorac Cardiovasc Surg 1996;112:238-47.

4. Feinberg MS, Waggoner AD, Kater KM, Cox JL, Lindsay BD, Perez JE. Restoration of atrial function after the maze procedure for patients with atrial fibrillation: assessment by Doppler echocardiography. Circulation 1994;90(Suppl):II285-92.

5. Chua YL, Schaff HV, Orszulak TA, Morris JJ. Outcome of mitral valve repair in patients with preoperative atrial fibrillation. Should the maze procedure be combined with mitral valvuloplasty? J Thorac Cardiovasc Surg 1994;107:408-15.

6. Cox JL, Schuessler RB, Lappas DG, Boineau JP. An 81/2-year clinical experience with surgery for atrial fibrillation. Ann Surg 1996;224:267-73.

7. McCarthy PM, Castle LW, Maloney JD, et al. Initial experience with the maze procedure for atrial fibrillation. J Thorac Cardiovasc Surg 1993;105:1077-87.

8. Sandoval N, Velasco VM, Orjuela H, et al. Concomitant mitral valve or atrial septal defect surgery and the modified Cox-maze procedure. Am J Cardiol 1996;77:591-6.

9. Kamata J, Kawazoe K, Izumoto $\mathrm{H}$, et al. Predictors of sinus rhythm restoration after Cox maze procedure concomitant with other cardiac operations. Ann Thorac Surg 1997;64:394-8.

10. Kosakai Y, Kawaguchi AT, Isobe F, et al. Modified maze procedure for patients with atrial fibrillation undergoing simultaneous open surgery. Circulation 1995;92(Suppl):II359-64.

11. Cox JL. Evolving applications of the maze procedure for atrial fibrillation (editorial). Ann Thorac Surg 1993;55:578-80.

12. Cox JL, Jaquiss RD, Schuessler RB, Boineau JP. Modification of the maze procedure for atrial flutter and atrial fibrillation. II. Surgical technique of the maze III procedure. J Thorac Cardiovasc Surg 1995;110:485-95.

13. Cox JL. The surgical treatment of atrial fibrillation. IV. Surgical technique. J Thorac Cardiovasc Surg 1991;101:584-92.

14. Cox JL, Schuessler RB, D'Agostino HJ Jr, et al. The surgical treatment of atrial fibrillation. III. Development of a definitive surgical procedure. J Thorac Cardiovasc Surg 1991;101:569-83.
15. Petersen P, Boysen G, Godtfredsen J, Andersen ED, Andersen B. Placebo-controlled, randomised trial of warfarin and aspirin for prevention of thromboembolic complications in chronic atrial fibrillation. The Copenhagen AFASAK study. Lancet 1989;1:175-9.

16. Stroke Prevention in Atrial Fibrillation Study. Preliminary report. N Engl J Med 1990;322:863-8.

17. The Boston Area Anticoagulation Trial for Atrial Fibrillation Investigators. The effect of low-dose warfarin on the risk of stroke in patients with nonrheumatic atrial fibrillation. N Engl J Med 1990;323:1505-11.

18. Connolly SJ, Laupacis A, Gent M, Roberts RS, Cairns JA, Joyner C. Canadian Atrial Fibrillation Anticoagulation (CAFA) Study. J Am Coll Cardiol 1991;18:349-55.

19. The European Atrial Fibrillation Trial Study Group. Optimal oral anticoagulant therapy in patients with nonrheumatic atrial fibrillation and recent cerebral ischemia. N Engl J Med 1995;333:5-10.

20. EAFT (European Atrial Fibrillation Trial) Study Group. Secondary prevention in non-rheumatic atrial fibrillation after transient ischaemic attack or minor stroke. Lancet 1993;342: 1255-62.

21. Fihn SD. Aiming for safe anticoagulation (editorial). N Engl J Med 1995;333:54-5.

22. Atrial Fibrillation Investigators. Risk factors for stroke and efficacy of antithrombotic therapy in atrial fibrillation: analysis of pooled data from five randomized controlled trials. Arch Intern Med 1994;154:1449-57.

23. Stroke Prevention in Atrial Fibrillation Investigators. Adjusteddose warfarin versus low-intensity, fixed-dose warfarin plus aspirin for high-risk patients with atrial fibrillation: Stroke Prevention in Atrial Fibrillation III randomised clinical trial. Lancet 1996;348:633-8.

24. Gage BF, Cardinalli AB, Albers GW, Owens DK. Cost-effectiveness of warfarin and aspirin for prophylaxis of stroke in patients with nonvalvular atrial fibrillation. JAMA 1995;274:1839-45.

25. Josephson ME. Antiarrhythmic agents and the danger of proarrhythmic events. Ann Intern Med 1989;111:101-3.

26. The Cardiac Arrhythmia Suppression Trial (CAST) Investigators. Preliminary report: effect of encainide and flecainide on mortality in a randomized trial of arrhythmia suppression after myocardial infarction. N Engl J Med 1989;321:406-12.

27. Coplen SE, Antman EM, Berlin JA, Hewitt P, Chalmers TC. Efficacy and safety of quinidine therapy for maintenance of sinus rhythm after cardioversion: a meta-analysis of randomized control trials. Circulation 1990;82:1106-16.

28. Sueda T, Nagata H, Orihashi K, et al. Efficacy of a simple left atrial procedure for chronic atrial fibrillation in mitral valve operations. Ann Thorac Surg 1997;63:1070-5

29. Cox JL, Boineau JP, Schuessler RB, Jaquiss RD, Lappas DG. Modification of the maze procedure for atrial flutter and atrial fibrillation. I. Rationale and surgical results. J Thorac Cardiovasc Surg 1995;110:473-84.

30. Sgarbossa EB, Pinski SL, Maloney JD, et al. Chronic atrial fibrillation and stroke in paced patients with sick sinus syndrome: relevance of clinical characteristics and pacing modalities. Circulation 1993;88:1045-53. 